\title{
BEM ANALYSES ON HALF-CELL POTENTIAL MEASUREMENT AND CURRENT FLOW
}

\author{
Veerachai LEELALERKIET ${ }^{1}$, Je-Woon KYUNG ${ }^{2}$ and Masayasu OHTSU $^{3}$ \\ ${ }^{1}$ Member of JSCE, Ph.D Student, Graduate School of Science and Technology, Kumamoto University \\ (Kurokami 2-39-1, Kumamoto 860-8555, Japan) \\ ${ }^{2}$ Member of JSCE, Ph.D Student, Graduate School of Science and Technology, Kumamoto University \\ (Kurokami 2-39-1, Kumamoto 860-8555, Japan) \\ ${ }^{3}$ Member of JSCE, Dr.Eng., Professor, Graduate School of Science and Technology, Kumamoto University \\ (Kurokami 2-39-1, Kumamoto 860-8555, Japan)
}

\begin{abstract}
Numerical analysis of electric potentials and currents inside reinforced concrete is performed to study nondestructive evaluation of corrosion by the half-cell potential measurement and polarization resistance method. Electric fields around reinforcing steels are analyzed by using the Boundary Element Method (BEM). 3-dimensional analysis is conducted to compare with 2-dimensional analysis. Distributions of potentials inside concrete and current flows around rebars are clarified three-dimensionally.
\end{abstract}

Key Words: Boundary Element Method (BEM), half-cell potential, current flow

\section{INTRODUCTION}

Corrosion problems arise in reinforced concrete structures in recent decades. The corrosion process produces current flows on rebars in which the corrosion products increase with the time and develop severe cracks in concrete. Hence, early monitoring is needed to avoid the corrosion reaching to the harmful state. To this end, nondestructive evaluation techniques are developed and the practical applications based on the half-cell potential and the polarization resistance are extensively reported $^{1)}$. The half-cell potential measurement detects the potential differences between a reference electrode and a working electrode (rebar), which are converted into the probability of corrosion after ASTM C987. The polarization resistance method is associated to corrosion current rate. It is known that the potentials measured are easily affected by such factors as moisture condition of cover concrete, carbonation and/or chloride contents, because they are measured on the surface of concrete. Consequently, it is desirable that distributions of potentials and current flows inside concrete are theoretically estimated in advance of the measurements. Previously, two-dimensional (2-D) FDM analysis is conducted ${ }^{2)}$. In order to make it comparable to the actual measurement, three-dimensional (3-D) solutions are preferable. Therefore, the problems are restudied by the 3-D boundary element method (BEM), in comparison with 2-D solution.

\section{BEM ANALYSIS}

The concrete is treated as a medium, having electric resistance $R$ in domain $\mathrm{D}$. The governing equation is satisfied with the following Laplace 's equation,

$$
\nabla^{2}(u / R)=0 \quad \text { in } \mathrm{D},
$$

where $\nabla$ is the gradient (nabla) operator, $u$ is electric potential. In the case that concrete is homogeneous and $R$ is constant, Eq. 1 becomes,

$$
\nabla^{2} u=0 \quad \text { in } \mathrm{D} \text {. }
$$

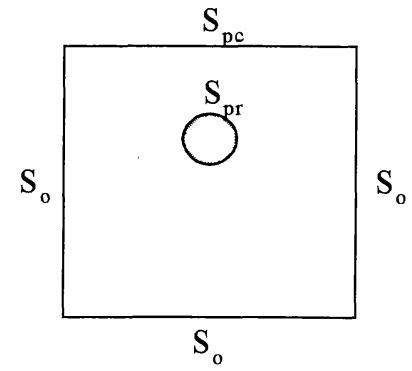

Fig.1 Boundary conditions of concrete under corrosion.
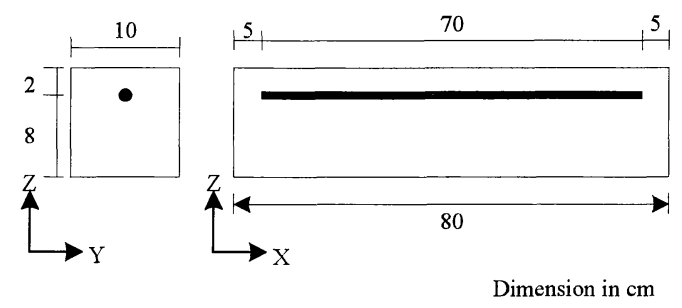

Fig. 2 Reinforced concrete beam model. 
Corresponding to the half-cell potential measurement and the polarization resistance method, the boundary conditions are prescribed in Fig.1. A counter electrode is placed on the surface of cover concrete, setting different electric potentials on a working electrode (rebar). The boundary conditions of potentials are defined on concrete surface, $S_{p c}$ and around embedded rebar, $S_{\mathrm{pr}}$. Another boundary $\mathrm{S}_{\mathrm{o}}$ is electrically free where outward flow of the current is equal to zero. These boundary conditions are given,

$$
\begin{array}{ll}
u_{1}=E_{1} & \text { on } \mathrm{S}_{\mathrm{pc}} \\
u_{2}=E_{2} & \text { on } \mathrm{S}_{\mathrm{pr}} \\
\frac{\partial}{\partial n}(u / R)=0 & \text { on } \mathrm{S}_{\mathrm{o}} .
\end{array}
$$

Here $E_{1}$ is the applied potential to the electrode. $E_{2}$ is the potential on corroded rebar and $n$ is the outward normal vector to the surface. In Fig.1, in the case that the counter electrode does not cover the whole surface on $S_{p c}$, the boundary conditions on the remained portion is defined as equation (3.c).

In the case that concrete is homogeneous, solution $u(x)$ at point $x$ can be solved by the boundary integral equation,

$$
\frac{1}{2} u(x)=\int_{S}\left[G(x, y) \frac{\partial u}{\partial n}(y)-\frac{\partial G}{\partial n}(x, y) u(y)\right] d S,
$$

where $\mathrm{S}=\mathrm{S}_{\mathrm{pc}}+\mathrm{S}_{\mathrm{pr}}+\mathrm{S}_{\mathrm{o}}$ and points $y$ are located on the boundary $\mathrm{S}$ surrounding the concrete. $G(x, y)$ is the fundamental solution, as follows;

$$
\begin{array}{ll}
G(x, y)=\frac{1}{2 \pi} \ln \frac{1}{r} & \text { in 2-D space } \\
G(x, y)=\frac{1}{4 \pi r} & \text { in 3-D space }
\end{array}
$$

Here $r$ is the distance between $x$ and $y$. The boundary is discretized into boundary meshes, prescribing potential $u_{j}$ and current $\frac{\partial u_{j}}{\partial n}$ at point $x_{j}$ on a boundary mesh. Digitizing Eq.4, a set of linear algebraic equations are obtained,

$\sum_{j=1}^{N}\left[\frac{\delta_{i j}}{2}-\frac{\partial G_{i j}}{\partial n}\right]\left\{u_{j}\right\}=\sum_{j=1}^{N}\left[G_{i j}\right\}\left\{\frac{\partial u_{j}}{\partial n}\right\}(i=1, N)$,

where $N$ is the number of boundary meshes, $\delta_{i j}$ is Kronecker's delta and $G_{i j}$ is the digitized fundamental solution between points $x_{i}$ and $x_{j}$. It is noted that concrete resistance is not taken into account in the present study. This is because mathematically it has nothing to do with potentials on the boundaries, although current values may change. Therefore, only the ratios of current flows are taken into consideration.

\section{SIMULATION MODEL}

Referring to the 2-dimensional model ${ }^{2)}, 3-\mathrm{D}$ analysis is conducted with the same configuration. The beam model has a square section of $10 \mathrm{~cm} \times 10$ $\mathrm{cm}$ and $80 \mathrm{~cm}$ in length. A rebar in $10 \mathrm{~mm}$ diameter

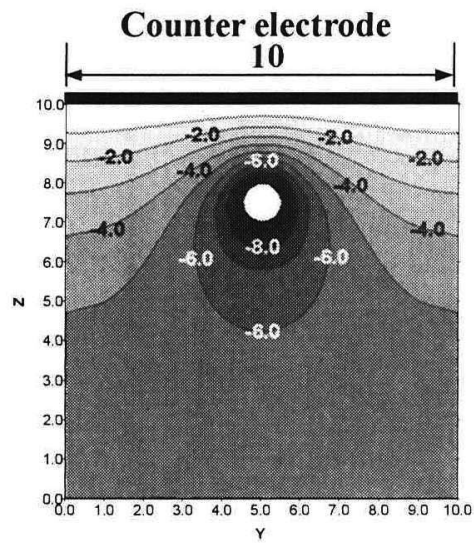

(a) Rectangular plate

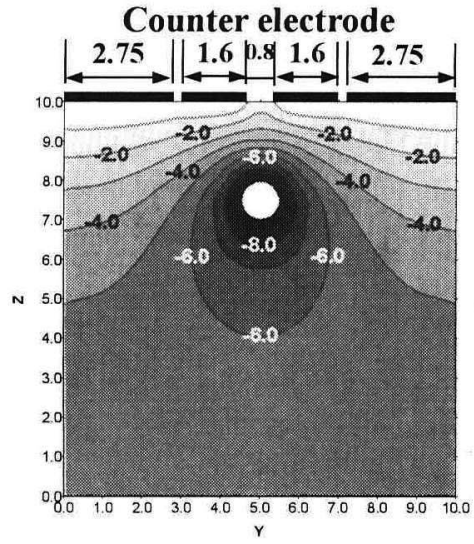

(b) Double-disk

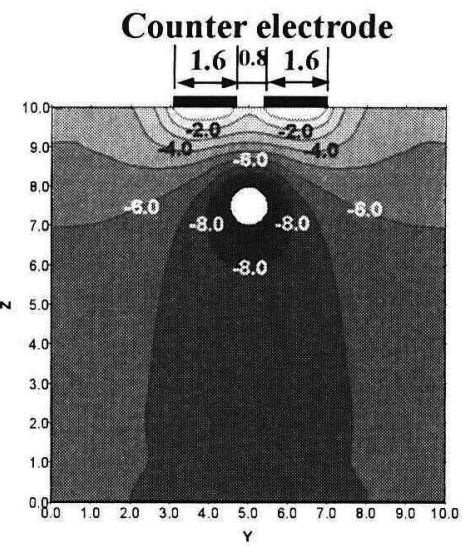

(c) Central-disk

Fig.3 2-D potential distribution of cross-section (unit in V). 
is embedded at $2 \mathrm{~cm}$ cover thickness with $70 \mathrm{~cm}$ long as shown in Fig.2.

Three types of counter electrodes are considered. One is a rectangular plate, which covers the whole surface of concrete as shown in Fig.3 (a). Another is a double-disk type, which illustrated in Fig.3 (b), both the guard and the central-counter electrodes are modeled. The other employs only a central-counter electrode (see Fig.3 (c)). A detail of double-disk counter electrode for Fig.3 (b) is illustrated in Fig.4

For all three types of the electrode, the boundaries of counter electrode and around the surface of rebar are set as $E_{1}=0.0$ volt and $E_{2}=$ -10.0 volts, respectively.

For BEM analysis, the boundaries of both cross-sectional and longitudinal models are divided into an element length of $0.25 \mathrm{~cm}$ as shown in Fig.5. Fig. 6 shows meshes and boundary conditions on the concrete surface of 3-D models. In the case of rectangular electrode, the size of the element is defined as $1 \mathrm{~cm}$ by $1 \mathrm{~cm}$ for the entire of concrete surface as illustrated in Fig.6 (a). In the double-disk and the central-disk, only the elements on the counter electrode are different from the rectangular element by dividing into small elements with the size $0.25 \mathrm{~cm}$ by $0.25 \mathrm{~cm}$ as show in Fig.7 (a) and (b). For the model of rebar in 2-D analysis, a cross-section of rebar is divided into 24 segments as shown in Fig. 7 (c). Regarding to the current flows, rebar surface (interface with concrete) is separated

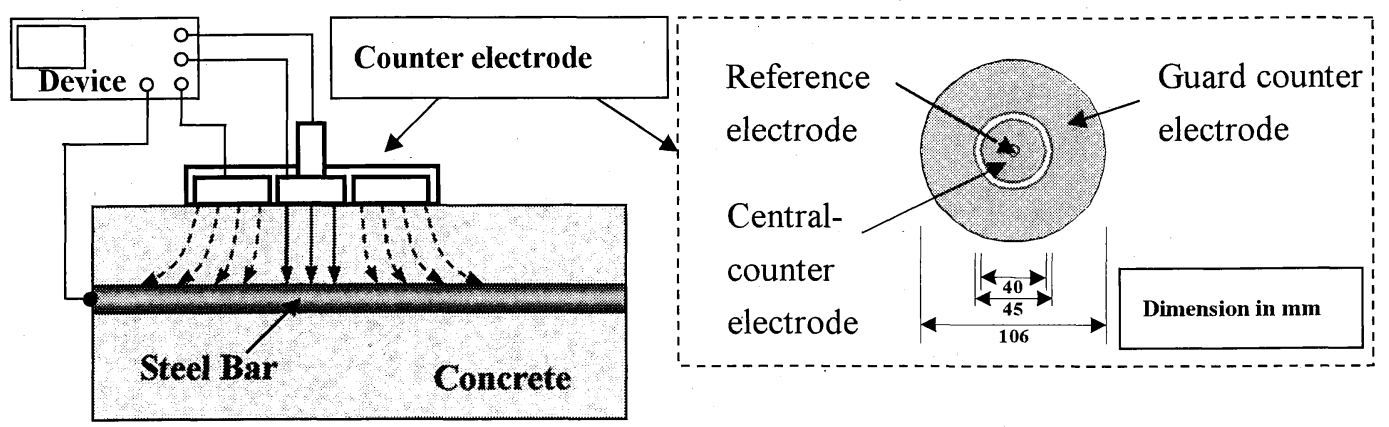

Fig.4 Double-disk type of counter electrode.

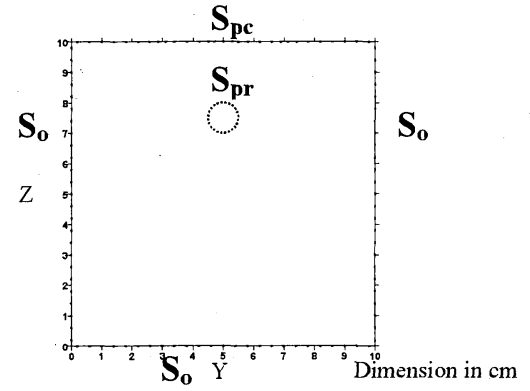

(a) Cross-sectional model

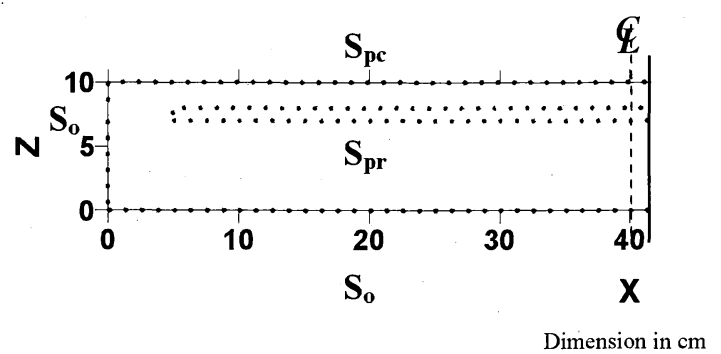

(b) Longitudinal model

Fig.5 Meshes and boundary condition of 2-D BEM analysis.

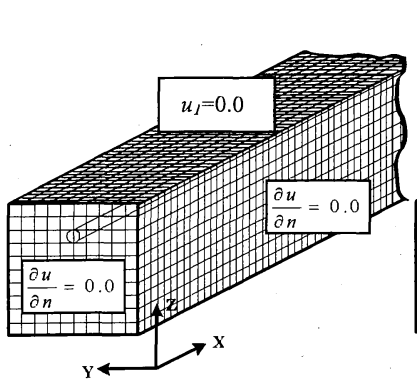

(a) 3-D rectangular electrode

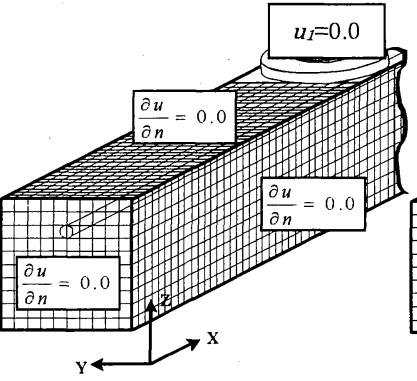

(b) 3-D Double-disk

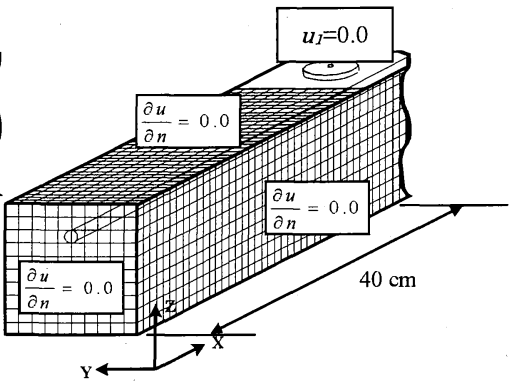

(c) 3-D central-disk

Fig.6 Meshes and boundary conditions of 3-D BEM model. 


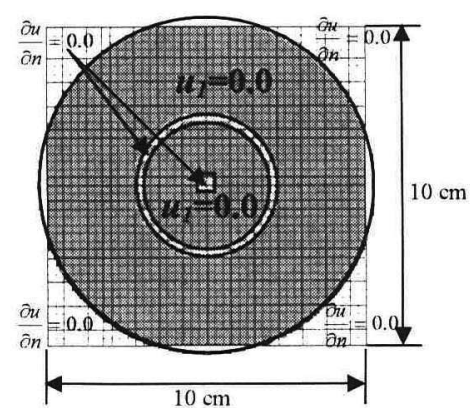

(a) Double-disk meshes

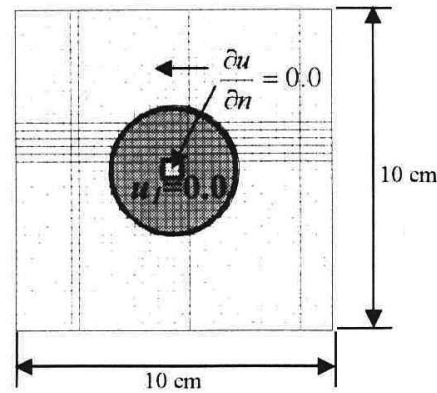

(b) Central-disk meshes

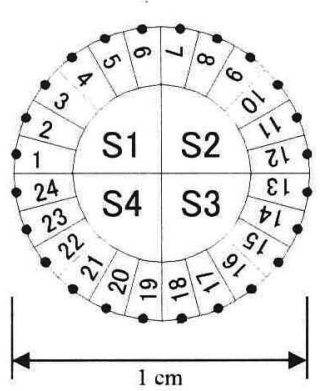

(c) 24-segments of rebar

Fig. 7 Mesh on counter electrodes and rebar.

into 4 parts. For an example, the upper left S1 corresponds to the summation of current on the segment numbers 1 to 6 . S2, S3 and S4 represent the summations of segments 7-12, 13-18 and 19-24, respectively. Thus, results of the current analysis are presented in the term of upper and lower current ratios. The upper current ratio is obtained by the summation of currents of $\mathrm{S} 1$ and $\mathrm{S} 2$ divided by the total currents, $\mathrm{S} 1+\mathrm{S} 2+\mathrm{S} 3+\mathrm{S} 4$. For the lower current ratio, $\mathrm{S} 3+\mathrm{S} 4$ is divided by the total. In 3-D analysis, a cross-section of rebar is divided as same as 2-D model. The sections of rebars in longitudinal direction are divided into $2 \mathrm{~cm}$ for all types of counter electrodes, except the portions of rebars beneath the counter electrode. In the cases of the double-disk and central-disk electrodes, they are divided into $0.25 \mathrm{~cm}$.

\section{RESULTS AND DISCUSSION}

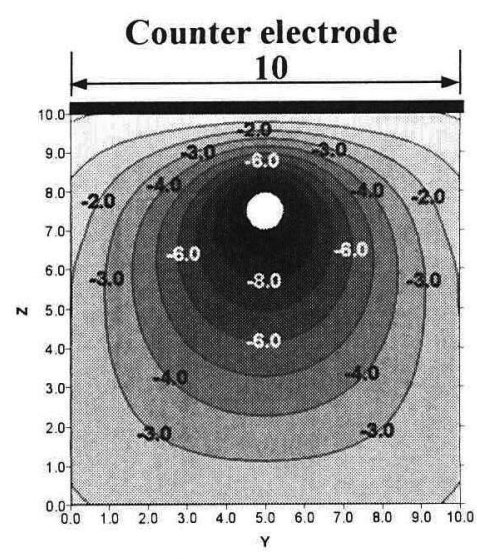

(a) Rectangular plate

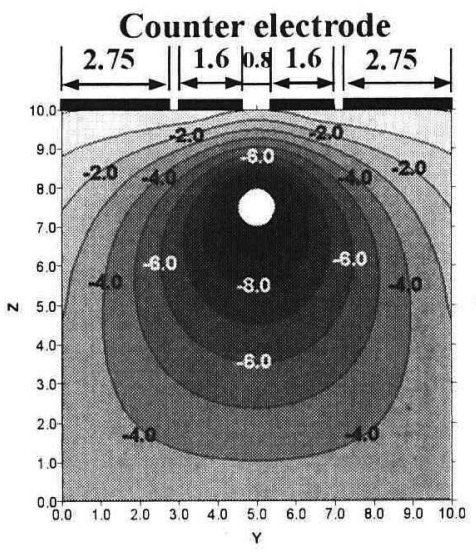

(b) Double-disk

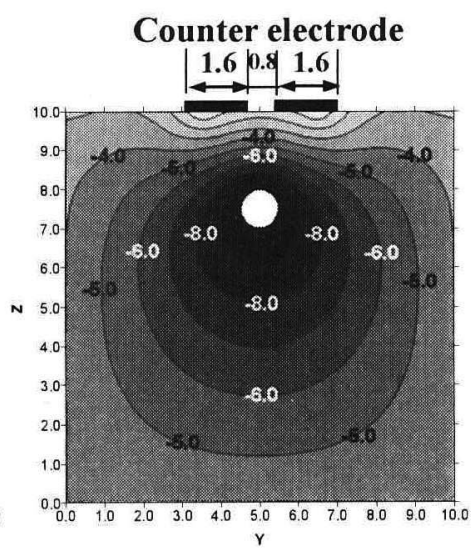

(c) Central-disk

Fig. 8 3-D potential distribution of the cross-section at middle span of beam (unit in V). 


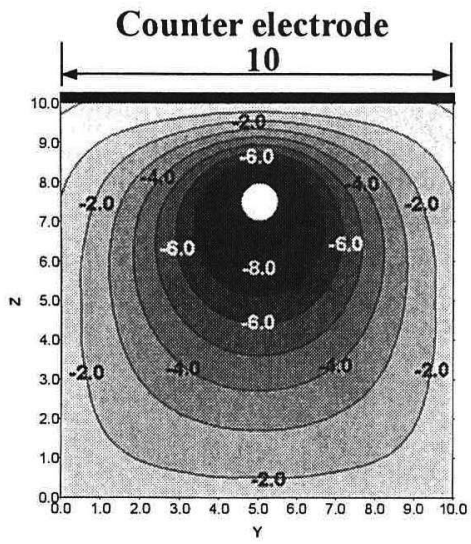

(a) Rectangular plate

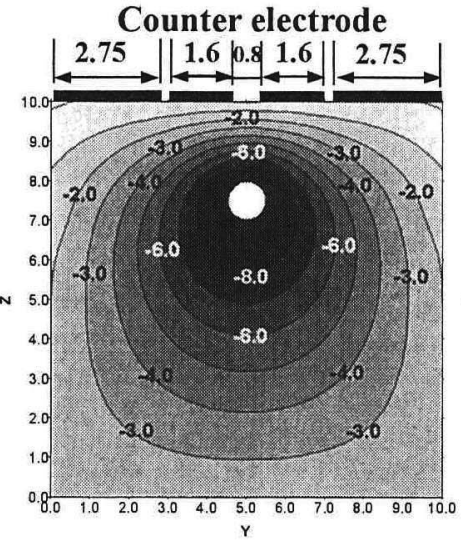

(b) Double-disk

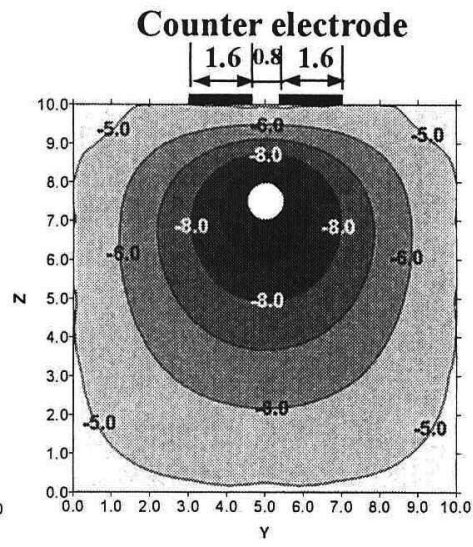

(c) Central-disk

Fig.9 3-D potential distribution of the cross-section at end of rebar (unit in V).

contours of potentials are similar to those of the counter electrode placed on the middle span of the beam in Fig.8, except the central-disk electrode. The values of potentials of near the outer boundaries are varied with the sizes of counter electrodes and become slightly lower negative than those obtained in Fig.8. Compared to 2-D analysis in Fig.3, the distributions of potentials are totally different from those results. This means that 2-D analysis of potentials is not so sufficient to clarify the effect of the counter electrode as 3-D analysis.

\section{(2) Potential distribution of longitudinal section}

Referring to 2-D potential distribution in Fig.10, which is again referred to those of the literature ${ }^{2)}$, it is found that the distributions of potentials are observed locally in both the rectangular electrode and the double-disk electrode models. Especially in the double-counter electrode model, the distribution of potential is seen only the area near the counter electrode. In 3-D model, in contrast, the potentials distribute entire the beam in the both cases of the rectangular electrode and the double-disk electrode as shown in Fig.11.

Again, the potential distributions in the 3-D solutions are totally different from those of the 2-D. Contour lines are open in the latter, while those are closed in the former. This implies that 3-D analysis is desirable to simulate the half-cell potential measurement.

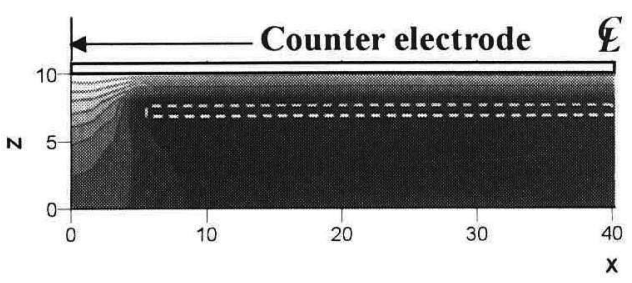

(a) Rectangular plate

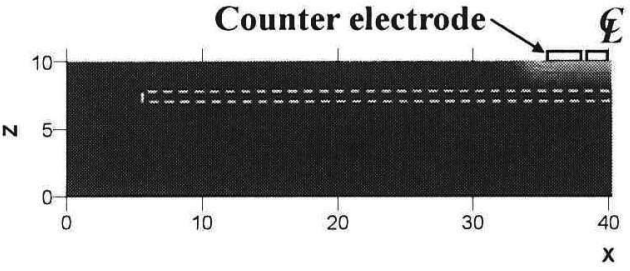

(b) Double-disk

Fig.10 2-D Longitudinal potential distribution (unit in V).

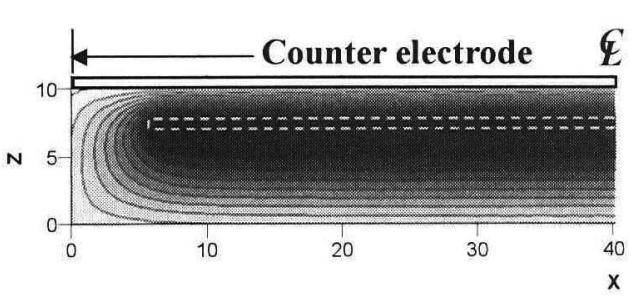

(a) Rectangular plate

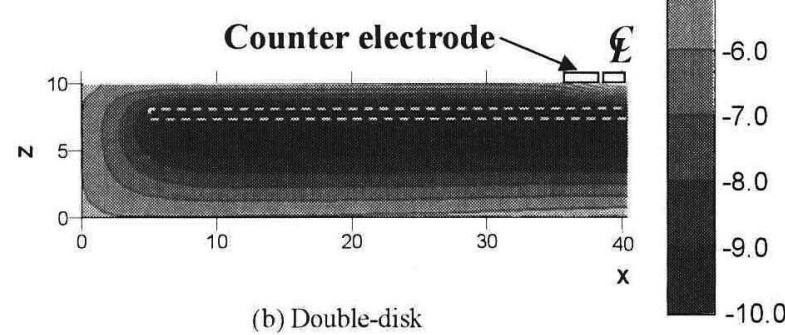

(b) Double-disk

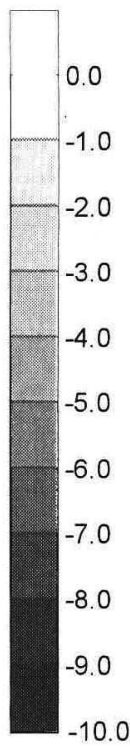

Fig.11 3-D Longitudinal potential distribution (unit in V). 


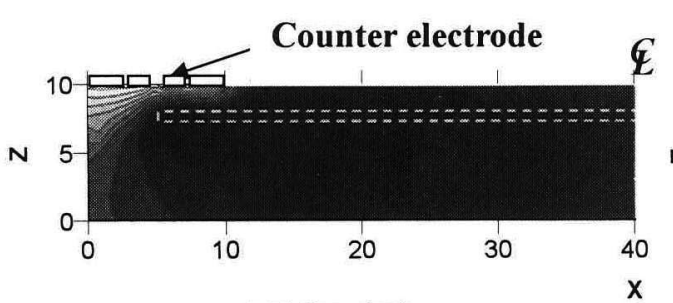

(a) 2-D analysis

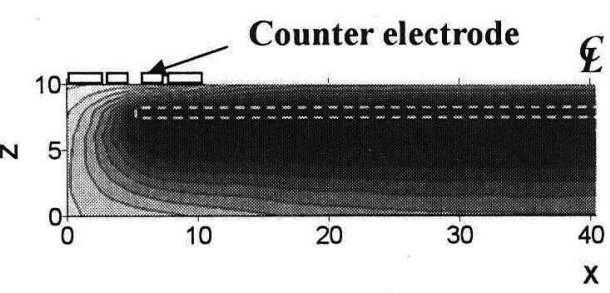

(b) 3-D analysis

Fig.12 Longitudinal potential distribution in case of double-disk electrode over the end of rebar (unit in V).

The potential distributions of longitudinal sections when the double-disk electrode placed on the end of rebar are shown in Fig.12. Result of 2-D model is shown in Fig.12 (a). It is observed that the left-half of the counter electrode can influence through the bottom surface of concrete, because there is no rebar in this area. While the influence of right-half of the counter electrode is found only the area between the rebar and counter electrode as show in Fig.12 (a), the distribution of potential by 3-D analysis is illustrated in Fig.12 (b). Similar to the Fig.11 (b), the potentials distribute entire the beam and the influence of counter electrode is clearly found on the area beneath the counter electrode. This result implies that the distributions of potentials are significantly different between the case that the counter electrode on the end of rebar and the other locations. Accordingly, it is concluded that the 3-D analysis can effectively simulate the distribution of half-cell potential both in the cross-sectional and the longitudinal directions.

\section{(3) Current flow on cross-section of rebar}

Current flows on the rebars in 2-D analysis are shown in Fig. 13, where the size and the direction of arrow represent the amount and the direction of the current. All currents in three models are negative and the current flow distributions on all rebars are very similar. Because the upper part of rebar is close to the counter electrode, the upper current ratios of all cases are larger than the lower current ratio.

As similar to the potential distribution of cross-section, the current distributions of the rectangular electrode are quite the same as the double-disk electrode. In the central-disk electrode, the upper current ratio is almost $65 \%$, because the small area of counter electrode could not affect much the lower part of rebar. The influence of counter electrode is also observed in the term of current values, the smaller area of counter electrode provides the lower current values. The 3-D current distributions on the cross-section of rebar at the mid-span of beam are shown in Fig.14. In the double-disk electrode and the central-disk electrode models, the counter electrodes are placed on the center of the beam. The current distributions on rebars are similar to the 2-D analysis. The upper current ratios of all cases in 3-D analysis are bigger than those of 2-D, especially in the central-disk electrode model. The differences of the current ratios among three counter electrodes in 3-D model are fairly large, compared to those of 2-D model.

In the double-disk electrode model, the current flows from the counter electrode are compared between 2-D model and 3-D model in Fig.15. The current distributions from the counter electrode of both models are similar. The current from centraldisk electrode of 2-D analysis is about $62 \%$ of total

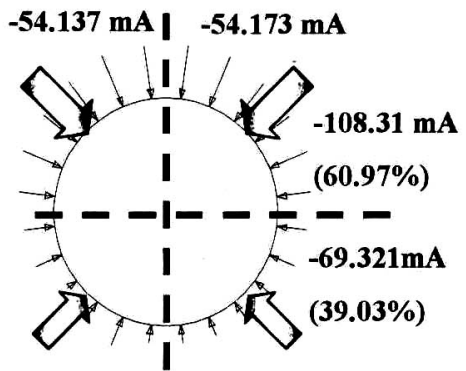

$-34.665 \mathrm{~mA}$ | $-34.656 \mathrm{~mA}$ $\mathbf{- 5 2 . 8 1} \mathrm{mA}$ | $\mathbf{- 5 2 . 8 4 5} \mathrm{mA}$

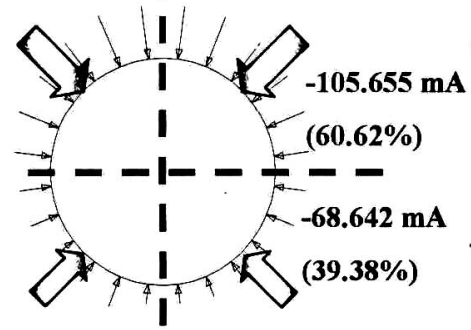

$-34.326 \mathrm{~mA} \mid-34.316 \mathrm{~mA}$
$-45.692 \mathrm{~mA} / \mathbf{- 4 5 . 7 2 2} \mathrm{mA}$

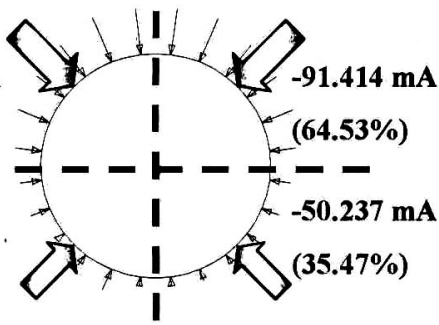

$-25.121 \mathrm{~mA}$ | $-25.116 \mathrm{~mA}$
(a) Rectangular electrode

(b) Double-disk electrode

(c) Central-disk electrode 


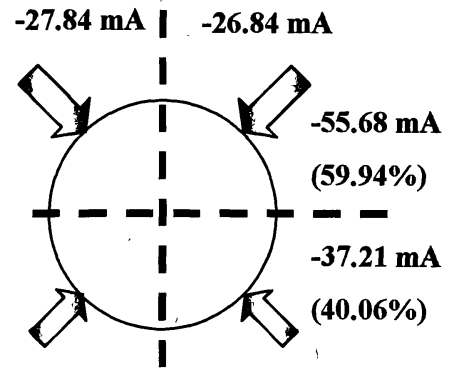

$-18.61 \mathrm{~mA}$ | $-18.61 \mathrm{~mA}$
$-26.026 \mathrm{~mA}$ | $-\mathbf{2 6 . 0 2 5} \mathrm{mA}$

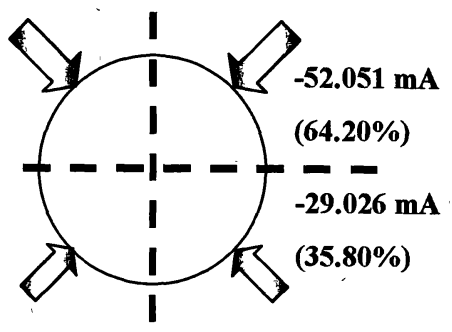

$-14.512 \mathrm{mAl}-14.514 \mathrm{~mA}$

(b) Double-disk electrode
$-18.405 \mathrm{~mA}$ | $-18.406 \mathrm{~mA}$

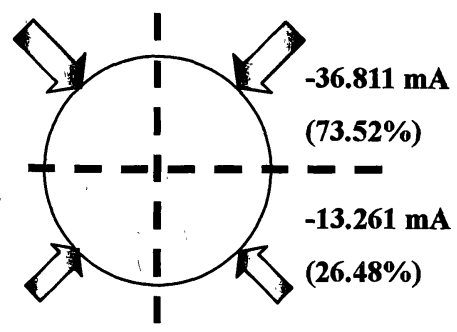

$-6.631 \mathrm{~mA} \mid-6.63 \mathrm{~mA}$

(c) Central-disk electrode

(a) Rectangular electrode

Fig.14 Current distribution on rebar in 3-D analysis at the center of beam.

currents of the whole area of the double-disk electrode, which corresponds to the upper current ratio of rebar as shown in Fig.13 (b). In 3-D analysis, the current from the central-disk electrode is $52 \%$, which is less than the current on the upper rebar (see Fig.14 (b)). Hence, it is roughly summarized that not only the current from the central-disk, but also the current from the guard disk contribute to the upper current of rebar. In other words, the

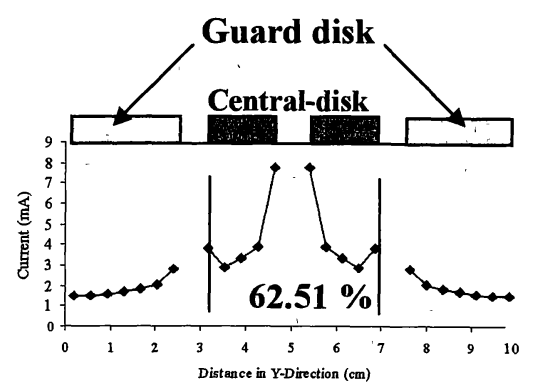

(a) 2-D model

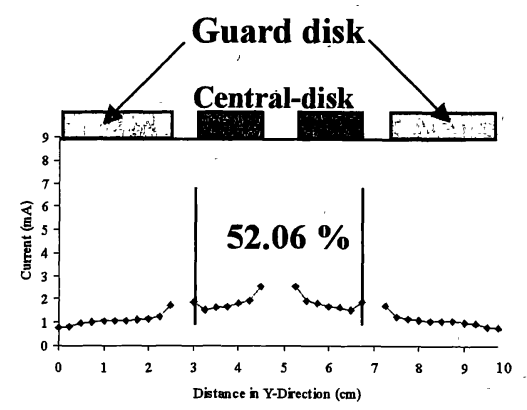

(b) 3-D model

Fig.15 Current from counter electrodes in the double-disk counter electrode. guard-disk can confine the current within the central-disk area.

\section{(4) Locations of the electrode}

Concerning the current flow inside concrete, other positions of the counter electrodes are studied in the double-disk electrode and the central- disk electrode in 3-D analysis. The center of counter electrodes is placed at length $X=5 \mathrm{~cm}, 15 \mathrm{~cm}, 25$

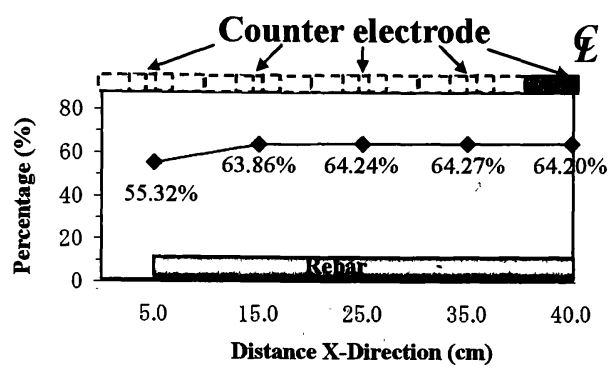

(a) Double-disk electrode

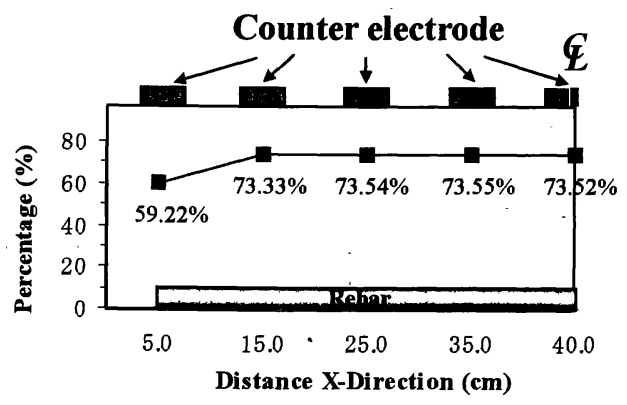

(b) Central-disk electrode

Fig.16 Upper current ratios of rebars in the double-disk counter electrode and the central-disk counter electrode. 
$\mathrm{cm}, 35 \mathrm{~cm}$ and $40 \mathrm{~cm}$, respectively. Results of upper current ratios at these cross-sections in the double-disk electrode and the central-disk electrode are shown in Fig.16. It is observed that the upper current ratios at the end of rebars in the both electrodes are smaller than those of the other positions. At the end of rebar, thus, the upper current ratio and the lower current ratio are not much different. This is because the lower part of rebar at this position is easily affected by the counter electrode. On the other hands, when the counter electrode is placed over the other positions of rebar, the influence of the counter electrode may not reach to the lower part of rebar. These results could not be obtained by 2-D analysis.

In the polarization resistance method, the polarization area is necessary to determine the corrosion rate ${ }^{2)}$. According to results of 2-D current distribution in Fig.13, the upper current and lower current ratios are not much different in the rectangular and the double-disk electrodes. It suggests that the polarized areas are the same in both counter electrodes. In 3-D analysis, it is clearly observed that the lower current ratio of the rectangular electrode is larger than that of the double-disk electrode. Although it was reported ${ }^{2)}$ that the polarized area of rebar could be calculated by considering the entire circumference of rebar and

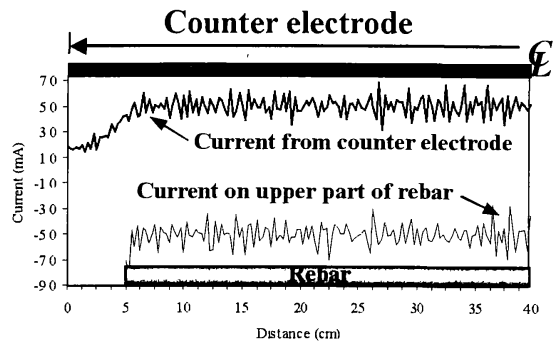

only the half-length of circumference of rebar in the rectangular and the double-disk electrodes, respectively, in the double-disk electrode placed on the end of rebar in Fig.16 (a), the upper current ratio is not much larger than the lower current ratio compared to other locations of the counter electrodes. Therefore, it may suggest that the polarized area, when the double-disk is placed on the end of rebar, is referred to entire circumference of rebar.

\section{(5) Current flow on longitudinal section of rebar}

2-D current distribution at the longitudinal section of the beam in the rectangular counter electrode and the double-disk electrode are shown in Figs.17 and 18, respectively. In the rectangular counter electrode model, the currents fluctuate around $5 \mathrm{~mA}$ and $-5 \mathrm{~mA}$ in the current from counter electrode and in the current on upper part of rebar, respectively. These sharply decrease at the end of the rebar. The current ratio is calculated and shown in Fig.17 (b), it is noted that upper current ratio is drastically larger than that of the lower. In the double-disk model, the currents on the upper part of the rebar are nearly equal to zero, except the end of rebar and the area under the counter electrode. Similar to the rectangular electrode, the lower current ratio is a few percent as shown in Fig.18 (b).

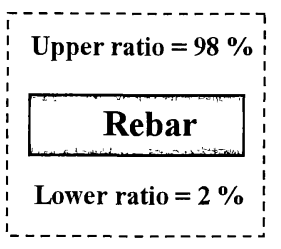

Fig.17 2-D analysis of the longitudianl section in the rectangular counter electrode.

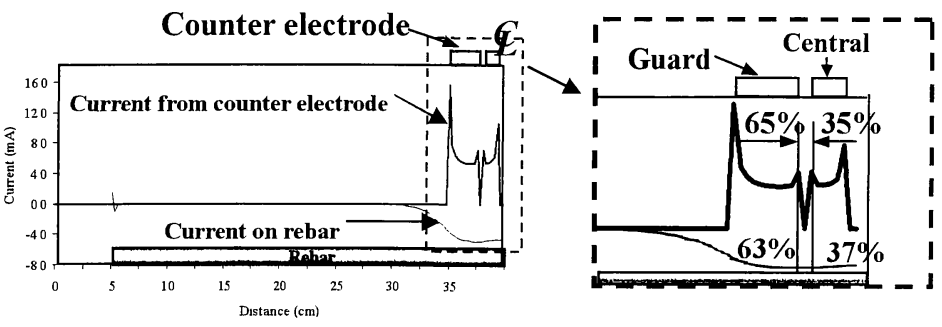

(a) Current distribution from counter electrode and on the upper part of rebar

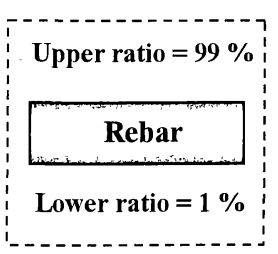

(b) Current ratio on rebar

Fig.18 2-D analysis of the longitudianl section in the double-disk counter electrode. 


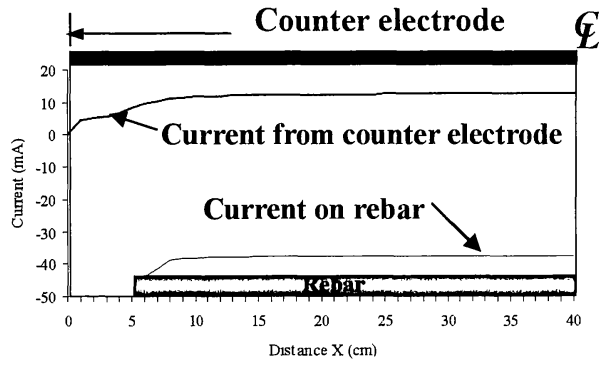

(a) Current distribution from counter electrode and on the upper part of rebar

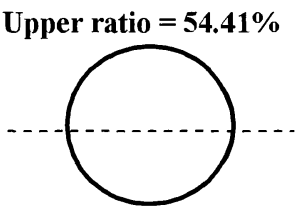

Lower ratio $=\mathbf{4 5 . 5 9 \%}$

(b) Current ratio on rebar

Fig.19 3-D analysis of the longitudianl section in the rectangular counter electrode.

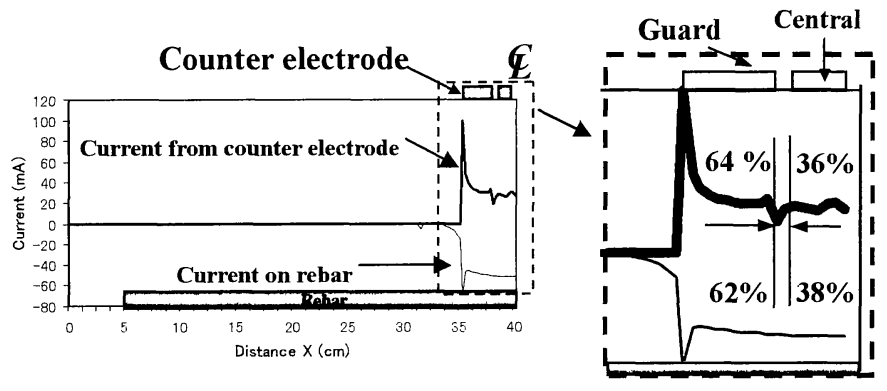

(a) Current distribution from counter electrode and on the upper part of rebar

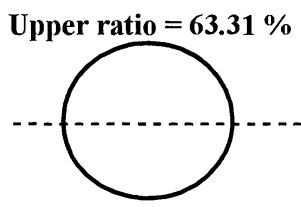

Lower ratio $=36.69 \%$

(b) Current ratio on rebar

Fig. 20 3-D analysis of the longitudianl section in the double-disk counter electrode.

From these results, it is summarized that the counter electrode influences only the upper part of rebar, which corresponds to the potential distributions of longitudinal section in Fig.11. Besides, the current ratios at the longitudinal section are totally different from those of the cross-section.

In 3-D solution, the current flows from the counter electrode and the current on the rebar in the case of the rectangular-counter electrode is shown in Fig.19. The currents distribute evenly along the length of rebar, except the area around the end of rebar. In contrast to 2-D analysis, the upper current ratio and lower current ratio are not much different as illustrated in Fig.19 (b).

Fig.20 shows the current distribution in the longitudinal direction of 3-D double-disk counter electrode model. The current distribution is fairly similar to 2-D analysis, except the current on the rebar beneath the edge of guard electrode. The sharp drop in current value is caused by the differences of size of mesh between inside and outside the counter electrode. The upper current ratio is higher than that of the lower ratio, which corresponds to the current distribution on the cross-section solution shown in Fig.20 (b). Thus, it is concluded that the current distribution in 2-D analysis is not reasonable. Thus,
3-D analysis is recommended to estimate electrical potentials and associated current flows.

The current intensity of the double-disk counter electrode in 2-D model is illustrated in the right-hand side of Figs.18 (a). It is observed that the current originated from the central-disk is about $35 \%$ of the whole area of double-disk electrode. Meanwhile, the upper current on rebar beneath the central-disk is about $37 \%$ of the total upper current on rebar. In 3-D model, the current intensity of double-disk electrode is shown in right-hand side of Fig.20 (a). It is noticed that the current intensity of central-disk is about $36 \%$ of the whole current of the double-disk electrode, which is slightly less than the upper current on the rebar beneath the central-disk. This means that the current on rebar under the central-disk electrode is comparable to the current from the central-disk in both 2-D and 3-D analyses.

The current distributions in the longitudinal direction of 2-D and 3-D analyses when the doubledisk electrode placed on the end of rebar are shown in Figs.21 and 22. In 2-D analysis, the current intensities on the upper part of rebar and the current flow from the right part of counter electrode are almost matched, which it is the same as the case of 

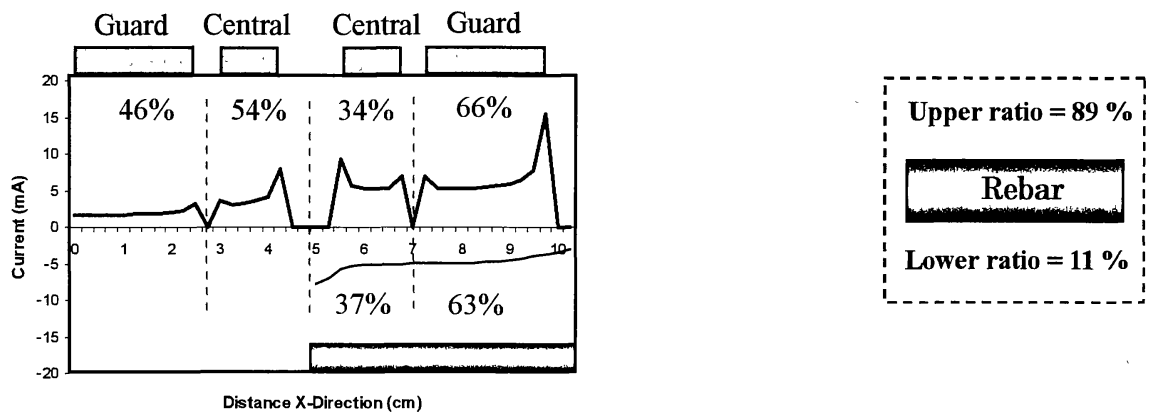

(a) Current distribution from counter electrode and on the upper part of rebar

(b) Current ratio on rebar

Fig.21 2-D analysis of the longitudianl section when double-disk counter electrode placed on the end of rebar.
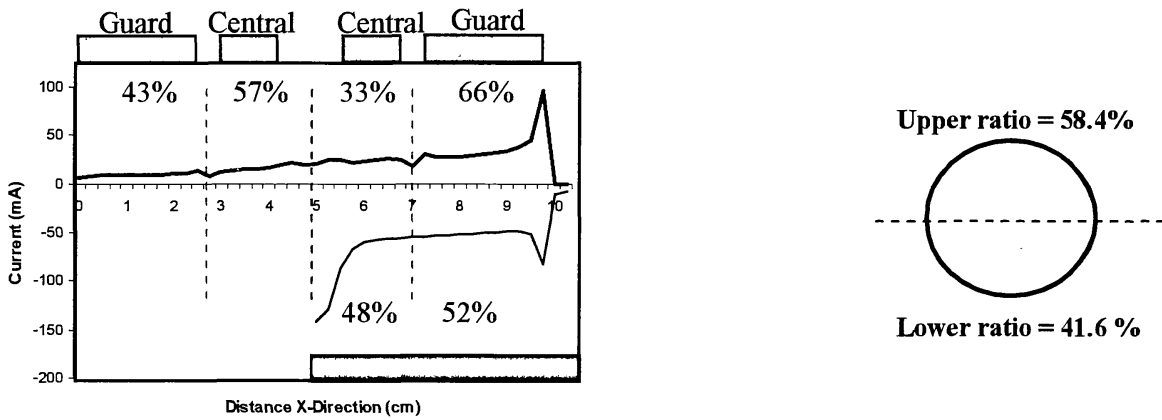

Lower ratio $=41.6 \%$

(a) Current distribution from counter electrode and on the upper part of rebar

(b) Current ratio on rebar

Fig.22 3-D analysis of the longitudianl section when double-disk counter electrode placed on the end of rebar.

the double-disk placed on the middle span of beam in Fig. 18(a). The current originated from the left-central electrode is larger than that of the right-central electrode. In Fig.21 (b), the upper current ratio is larger than the lower current ratio. In 3-D analysis, the current from the right-central electrode over the end of rebar is less than that of the left-central electrode. The current from the right-central electrode is significantly less than the current intensity on the upper part of rebar beneath the central electrode. The current intensity on the upper part of rebar is totally different from that obtained from the double-disk electrode placed on the middle span in Fig.20 (a). In Fig.22 (b), the lower current ratio is quite large when compared to the lower current ratio of the double-disk electrode placed on the middle part in Fig.20 (b).

Regarding to the polarized area, it is noticed that the polarized areas of rebars in 2-D analysis of the double-disk electrode are independent of the positions of the counter electrode. In 3-D analysis, the current flow from the electrode is matched to the intensity of current on upper rebar in the case of the double-disk electrode located on the middle part of the beam. In contrast, in the case that the double-disk electrode is placed on the end of rebar, the left-central electrode influence the lower part of rebar, corresponding to the large current ratio of the lower part of rebar in Fig.22 (b). In 3-D cross-sectional analysis, thus, it is summarized that the polarized areas of the double-disk electrode are defined by the entire circumference of rebar and by the half circumference of rebar for the counter electrode placed on the end of rebar and the other locations.

\section{CONCLUSION}

The results obtained in this research are concluded, as follows:

1. Regarding to the half-cell potential measurement, the distribution of potential inside concrete is studied. In 3-D analysis, it is found that the potential values inside concrete and the current ratios on rebar are closely related with the size of counter electrodes, although it is not 
clearly observed in the 2-D solution. The differences of contours of potentials reflect both the differences of the locations of counter electrode and types of counter electrodes in cross-sectional and longitudinal directions in 3-D solution.

2. In the polarization resistance method, the polarized area of rebar is associated with the current intensity on rebar, current ratio on rebar and the current flow from the counter electrode. In 2-D analysis, the polarized areas of rebars in the rectangular and the double-disk electrodes are difficult to separate in both cross-section and longitudinal section models. They are independent of the locations of counter electrode. In contrast, the polarized areas in 3-D analysis reflect the differences of types of counter electrodes as well as the positions of counter electrode. It is summarized that the entire circumference of rebar is suitable for the rectangular electrode and the double-disk electrode when placed on the end of rebar, while the half circumference of rebar is referred to the double-disk electrode when placed on the other locations of the rebar.

\section{REFERENCES}

1) Technical Committee Report TC-994, JCI, 2001.

2) Kobayashi, K. and Miyagawa, T.: Study on Estimation of Corrosion Rate of Reinforcing Steel in Concrete by Measuring Polarization Resistance, Proc. of JSCE, No.669/V-50, pp.173-186, 2001.

3) Kyung, J.W. and Ohtsu, M.: Study on Half-Cell Potential Measurement for NDE of Rebar Corrosion, Proc.9th Int.Conf. Structural Faults and Repair, London, 2001.

(Received December 18, 2002)

\section{自然電位測定に関する BEM 解析}

\section{Veerachai LEELALERKIET, Je-Woon KYUNG，大津政康}

\footnotetext{
自然電位測定の際のコンクリート内部の電位分布及び電流分布を明らかにするために，境界要素法（BEM）を 用いて数值解析を行った. 既報を参考に 2 次元解析と 3 次元解析を実施し, 各種の電極を用いて自然電位を測定 する場合にける電位と電流の分布を解明した。 その結果, 電位分布は, 2 次元解析と 3 次元解析ではかなり異な ることが判明した. 鉄筋への電流の流入に関しては，2 次元解析と 3 次元解析との差異は断面内分布では大きく なかったが，鉄筋方向に関してはかなり異なることが明らかになった。
} 